\title{
The Relationship Between Body Compositions of Taekwondo Practitioners Aged 14-16 and Their Aerobic Endurance
}

DUYGU SEVINÇ YILMAZ1 BURAKHAN AYDEMIR²

Erzincan Binali Yıldırım University, Sports Science Faculty, Department of Physical Education and Sports Teaching, Erzincan/ Turkey, 24duygusevinc24@gmail.com, Gsm: 054644687 69, ORCID: 0000-0002-7737-564X

${ }_{2}^{2}$ Karadeniz Teknik Universitesi, Rectorate Physical Education Department, Trabzon/Turkey, burakhanaydemir61@gmail.com, ORCID:0000-0003-3922-3693

Correspondence to: Burakhan Aydemir, Email: burakhanaydemir61@gmail.com

\begin{abstract}
Background: Taekwondo (TKD) is a combat sport practiced by millions of children, young people and adults around the world.1 It is an Olympic sports branch with many complex features and constant interaction between two opponents in the competitions, where attack-contact techniques are applied quickly, attacking techniques are strong2,3 but also have good flexibility.

Aim: This study has been carried out to identify the relationship between body composition of taekwondo practitioners aged 1416 who regularly practice taekwondo, and their aerobic endurance.

Methods: A total of 33 registered taekwondo practitioners (17 male, 16 female) participated to this study on a voluntary basis. The age, height, weight, and body mass index of all the athletes who took part in the study are 14.96 \pm 0.80 years, $162.59 \pm 11.59$ $\mathrm{cm}, 50.97 \pm 7.51 \mathrm{~kg}$ and $19.14 \pm 2.39 \mathrm{~kg} / \mathrm{m}^{2}$ respectively. The group who participated to the study practice taekwondo two days a week, for 2 hours each, for a period of 1.5 years. The aerobic endurance of taekwondo athletes was measured by 20 -meter-long Shuttle Run Test. In order to measure the body composition values of the athletes, measurements of skinfold thickness (biceps, triceps, subscapula, subrailiac) were carried out. In calculating the body density, the formula of Durning-Womersley was used; and in calculating the body fat percentage, the formula of Siri was employed. Data was evaluated by SPSS 22.0. The normality distribution of the data obtained at the end of the study was evaluated by Kolmogorov-Smirnov test and it was observed that the data was in line with normal distribution. Following the normalcy assessment, the relationship between body compositions and aerobic endurances was determined by Pearson Correlation analysis.

Results: It is possible to say that the body composition values of taekwondo practitioners aged 14-16 have positive and negative impact on their aerobic endurance. It is observed that as the values 20 -meter Shuttle Run test increases, fat percentage of athletes decreases.

Conclusion: It is concluded that the findings obtained from the research results support the literature, and that body composition and aerobic capacity are important as performance criteria in many studies. It is thought that it may be beneficial for the athletes to perform aerobic endurance exercises during the annual training periods to perform the necessary practices to optimize their body composition and improve their aerobic capacity.

Keywords: Taekwondo, Body Composition, Aerobic Endurance
\end{abstract}

\section{INTRODUCTION}

Sport is really important not only sedentary person but also athletes performance. It is especially concern about many sciences such as psychology, sociology, physiology, anatomy, biomechanics. ${ }^{1}$ Taekwondo (TKD) is a combat sport practiced by millions of children, young people and adults around the world. ${ }^{2}$ It is an Olympic sports branch with many complex features and constant interaction between two opponents in the competitions, where attack-contact techniques are applied quickly, attacking techniques are strong ${ }^{3,4}$ but also have good flexibility.

TKD competitions are held in 1.5 minutes long 3 rounds and a 1-minute rest break between rounds. In a weight class, competitions continue until the athlete is renewed. This means that the athlete will play 7-8 matches for the final competition in a normal competition day. Although the competition time seems short in TKD competitions, overall total of other competitions to be performed by the athlete during the day determines the energy metabolisms that the athlete will use.

TKD competitions include short-term high-intensity technique practice with rest intervals. ${ }^{5}$ This indicates that anaerobic capacity must be strong for a good performance. ${ }^{3,6,7}$ According to another explanation, TKD requires physiological demands such as low-fat percentage, high anaerobic power, rapid movement ability and explosive power. . $^{3,8,9}$ However, good anaerobic capacity alone is not enough. Because aerobic capacity is also needed for good anaerobic energy production synthesis. ${ }^{10}$ In addition, high aerobic capacity is very important to meet the metabolic needs needed in TKD competitions and facilitate recovery. ${ }^{3}$

Aerobic fitness, neuromuscular function and anthropometric characteristics, which are regularly evaluated in athletes and are among the components of physical fitness, are important determinants of performance. ${ }^{9,11}$ Height, body mass index, body fat percentage and lean body mass play an important role in the TKD branch. $^{12,13}$ In addition, since TKD is a weight sport, relative strength is an important element. ${ }^{13}$ Therefore, athletes pay attention to their body composition in order to compete in the weight class they determine and become successful.

TKD, as an Olympic sport, is a branch where physical, physiological, and technical capacity is important. To achieve an effective performance in competitions, it is important to have information about the capacities of the athletes. Having sufficient information can provide convenience to develop the missing characteristics of the athletes. In parallel, this study aims to determine the relationship between body composition and aerobic endurance of athletes between the ages of 14 and 16 who regularly practice TKD.

\section{MATERIAL AND METHODS}

33 licensed athletes (17 male, 16 female) in the 14-16 age group who actively participate in taekwondo participated in the research voluntarily. Athletes participating in the study regularly practice taekwondo for 1.5 years, 2 days a week, for 2 hours.

The study was carried out in accordance with the Principles of the Declaration of Helsinki, ${ }^{14}$ and the parents of the participants were informed so that the study could be carried out, and a voluntary consent form was signed for the athletes to be included in the study.

Measurement Methods: To record the measurements and tests, measurement forms were prepared, and the measurement values were recorded on these forms.

Data Collection: While the ages of the individuals establishing the sample were determined in years, their height was measured with an accuracy of $0.01 \mathrm{~cm}$ using the height scale on the bare scale, and their body weight was measured with an accuracy of $0.01 \mathrm{~kg}$ with a dobo (taekwondo dress) scale. Body mass index (BMI) was determined by dividing the obtained weight by the square of the height. ${ }^{15}$

(BMI): body weight $(\mathrm{kg}) /$ height2 $(\mathrm{m})$ 
To measure the aerobic endurance of the athletes, the 20meter shuttle run test (Shuttle Run Test) was applied on them. For body composition measurements, skinfold thickness (biceps, triceps, suprailiac, sub scapula) measurements were taken with the Skinfold caliper and body density was calculated according to Durning-Wormesley's formula ${ }^{16}$ and body fat percentage, lean body mass, and fat body mass were calculated according to the Siri equation. The body density calculation required for the application of the

Siri equation ${ }^{17}$ was made according to the DurninWomersley equation.

Durnin-Womersley body density equation:15:

$\mathrm{BD}=1.1553-0.0643 \times \mathrm{X}$ (Boy)

$\mathrm{BD}=1.1369-0.0598 \times \mathrm{X}($ Girl $)$

$\mathrm{BD}=$ Body Density Log $\mathrm{X}=(\mathrm{bi}+\mathrm{tr}+\mathrm{SS}+\mathrm{si})$

Siri Equation:16 Fat\% $=(4.95 / B D-4.50) \times 100$

$\mathrm{BD}=$ biceps skinfold thickness, $\operatorname{tr}=$ triceps skinfold thickness, $\mathrm{sC}=$ subscapula skinfold thickness, si =suprailiac skinfold thickness.

Data Analysis: In the research, descriptive analyzes were included to determine the demographic characteristics of the athletes and examine their distribution to the groups. Afterwards, Kolmogorov-Smirnov normality analysis was performed to determine the suitability of the data for parametric analysis. As the data showed normal distribution as a result of the analysis, Pearson Correlation analysis was performed, and the level of significance was determined as $p<0.05$.

\section{RESULTS}

Table 1 Shows the Demographic Characteristics of the Athletes

\begin{tabular}{|l|l|l|l|}
\hline Demographic Information & Min. & Max. & Average $\pm S S$ \\
\hline Age (year) & 14 & 16 & $14.96 \pm 0.80$ \\
\hline Height $(\mathrm{cm})$ & 135 & 184 & $162.59 \pm 11.59$ \\
\hline Body weight $(\mathrm{kg})$ & 40 & 67 & $50.97 \pm 7.51$ \\
\hline Body Mass Index (BMI) & 13.43 & 24.90 & $19.14 \pm 2.39$ \\
\hline
\end{tabular}

Table 1 shows the demographic characteristics of the athletes. According to the table, the average age of the athletes participating in the research is $14.96 \pm 0.80$ years, the average height is $162.59 \pm 11.59 \mathrm{~cm}$, the average body weight is $50.97 \pm 7.51$ $\mathrm{kg}$, and the average BMI is $19.14 \pm 2.39$.

Table 2: Values of Male Athletes Regarding Aerobic

Endurance and Body Composition Parameters

\begin{tabular}{|l|l|l|l|l|}
\hline Parameters & $\mathrm{n}$ & Average & SS & Min.- Max \\
\hline BMI & 17 & 19.41 & 2.92 & $13.43-24.90$ \\
\hline 20Cm Shuttle Run & 17 & 40.47 & 6.49 & $31.00-54.00$ \\
\hline Fat Percentage & 17 & 17.36 & 4.74 & $11.04-26.22$ \\
\hline Body Fat Mass & 17 & 9.46 & 3.70 & $4.42-17.22$ \\
\hline Lean Body Mass & 17 & 43.83 & 9.80 & $25.20-60.18$ \\
\hline
\end{tabular}

Considering the values of male athletes regarding aerobic endurance and body composition parameters are examined in Table 2, the mean value of $\mathrm{BMI}$ is $19.41 \pm 2.92$, the average value of $20 \mathrm{~m}$ shuttle run is $40.47 \pm 6.49$, the mean fat percentage is $17.36 \pm 4.74$, the mean body fat mass is $9.46 \pm 3.70$ and the mean lean body mass is $43.83 \pm 9.80$.

Table 3: Values of Female Athletes Regarding Aerobic Endurance and Body Composition Parameters

\begin{tabular}{|l|l|l|l|l|}
\hline Parameters & $n$ & Average & SS & Min.-Max \\
\hline BMI & 16 & 18.85 & 1.70 & $15.90-21.40$ \\
\hline 20 Cm Shuttle Run & 16 & 33.29 & 5.89 & $22.70-23.10$ \\
\hline Fat Percentage & 16 & 19.80 & 3.38 & $13.42-20.20$ \\
\hline Body Fat Mass & 16 & 12.20 & 2.79 & $6.98-18.68$ \\
\hline Lean Body Mass & 16 & 34.68 & 7.11 & $20.87-46.89$ \\
\hline${ }^{*}$ P & &
\end{tabular}

${ }^{* *} p<0,01$

Considering the values of female athletes regarding aerobic endurance and body composition parameters are examined in Table 3 , the mean value of $\mathrm{BMI}$ is $18.85 \pm 1.70$, the average value of $20 \mathrm{~m}$ shuttle run is $33.29 \pm 5.89$, the mean fat percentage is $19.80 \pm 3.38$, the mean body fat mass is $12.20 \pm 2.79$ and the mean lean body mass is $34.68 \pm 7.11$.

Table 4: The relationship between aerobic endurance and body composition of athletes

\begin{tabular}{|l|l|l|l|l|l|}
\hline & & BMI & $\begin{array}{l}\text { Fat } \\
\text { Percenta } \\
\text { ge }\end{array}$ & $\begin{array}{l}\text { Body Fat } \\
\text { Mass }\end{array}$ & $\begin{array}{l}\text { Lean Body } \\
\text { Mass }\end{array}$ \\
\hline $\begin{array}{l}20 \mathrm{~m} \text { Shuttle } \\
\text { Run Test } \\
\text { (Male) }\end{array}$ & $\mathrm{R}$ &, 318 &,- 192 &, 176 &, $658^{* *}$ \\
\hline $\begin{array}{l}20 \mathrm{~m} \text { Shuttle } \\
\text { Run Test } \\
\text { (Female) }\end{array}$ & $\mathrm{P}$ &, 213 &, 461 &, 498 &, 004 \\
\hline & $\mathrm{P}$ &, 541 & 322 &,$- 573^{*}$ &, 034 \\
\hline
\end{tabular}

${ }^{*} \mathrm{p}<0,05$

As can be seen in Table 3, as a result of the analysis, it is seen that there is a positive medium level relationship between the $20 \mathrm{~m}$ shuttle run and the lean body mass of male athletes. On the other hand, for the female athletes, it is seen that there is a moderately significant negative correlation between $20 \mathrm{~m}$ shuttle run and body fat mass.

\section{DISCUSSION}

In this study, conducted to determine the relationship between the body compositions and aerobic endurance of the athletes between the ages of 14-16, it is seen that there is a positive and moderately significant relationship between the $20 \mathrm{~m}$ shuttle run and the lean body mass of male athletes. On the other hand, for the female athletes, it is seen that there is a moderately significant negative correlation between $20 \mathrm{~m}$ shuttle run and body fat mass. In other words, as the $20 \mathrm{~m}$ shuttle run value increases in male athletes, the lean body mass also increases. On the other hand, for the female athletes, as the $20 \mathrm{~m}$ shuttle run value increases, body fat mass decreases.

It is stated that there may be differences in body structures and sportive performances with the effect of growth and development in children and adolescents who do sports. Performance indicators can be directly related to parameters such as height, body weight, and body composition. ${ }^{18}$ Factors such as experience, endurance, body composition and anaerobic-aerobic power are also extremely important in evaluating the performance of athletes. ${ }^{19,20}$

In 2011, Kim et al. applied TKD training to 31 sedentary women aged 15-16 for 12 weeks. They found that as a result of the applied TCD training, muscle fitness and flexibility improved, as well as a decrease in body fat percentage and body fat mass. ${ }^{21}$ In our study, they state that women who do routine TCD training have a decrease in body fat mass. This study in the literature supports our study.

According to Stanforth et al., body composition plays an important role in determining elite athletes. ${ }^{22}$ As one of the healthrelated elements of physical fitness, anaerobic-aerobic capacity and body fat percentages are closely related to endurance. ${ }^{23,24,25}$ These findings are parallel with our study.

In another study examining the relationship between skill, speed, reaction time and body mass index of taekwondo players, the mean BMI was reported as $20.9 \pm 1.4 \mathrm{~kg} / \mathrm{m}^{2}$ in female athletes with an average age of $13.7 \pm 1.5$ years. In male athletes, the mean $\mathrm{BMI}$ was found to be $19.2 \pm 2.8 \mathrm{~kg} / \mathrm{m} 2 .^{26}$ When these findings are compared with our study, it is determined that the average BMI of female athletes is higher than our results, while the findings of male athletes are the same.

In the study conducted by Badem et al. on taekwondo players, the mean age of women is $16.68 \pm 1.95$ years, mean $\mathrm{BMI}$ is $21.3 \pm 2.62 \mathrm{~kg} / \mathrm{m}^{2}$, body fat percentage is $23.36 \pm 5.78$, body fat mass is $14.22 \pm 5.37 \mathrm{~kg}$ and lean body mass is $45.31 \pm 5.53 \mathrm{~kg} .{ }^{27} \mathrm{lt}$ is seen that all parameters are higher than the data of our study.

In the study examining the relationship between the somatotype structures and performance characteristics of 11-13 years old male taekwondo players, the average BMI of the athletes 
is $19.98 \pm 3.79 \mathrm{~kg} / \mathrm{m}^{2}$. In the study, it is seen that there is a significant relationship with strong negative aspect between $20 \mathrm{~m}$ shuttle run value and endomorphic body type, and a moderately significant negative relationship between mesomorphy body type. In other words, as the shuttle run value increases, the fat rate decreases. It is indicated that there is a moderately significant positive correlation between the shuttle run value of $20 \mathrm{~m}$ and the ectomorph body type. As the shuttle run value increases, so does the proportion of body muscularity. ${ }^{28}$ The data obtained as a result of the literature review is parallel with our study.

According to Bridge et al., elite and sub-elite taekwondo players have low body fat level and a structure representing moderate muscle ratio. Athletes perform in many competitions during the day. Athletes must have moderate to high aerobic capacity to meet recovery and metabolic needs. ${ }^{3}$

The high aerobic endurance of taekwondo players contributes to better performance and late fatigue of them. In competitions, the performance of the athlete, especially in the last seconds of the round, can determine whether the match can be won or not. Therefore, intense fatigue in the last seconds may cause the athlete to lose the competition. From this perspective, it is important for TKD athletes to develop their aerobic endurance at an optimal level. ${ }^{29}$

\section{CONCLUSION}

It is concluded that the findings obtained from the research results support the literature, and that body

composition and aerobic capacity are important as performance criteria in many studies. It is thought that it may be beneficial for the athletes to perform aerobic endurance exercises during the annual training periods to perform the necessary practices to optimize their body composition and improve their aerobic capacity.

\section{REFERENCES}

1. Celik, A Zengin, S. \& Mustafa, B. A. S. (2017). Determination Of Aggression Levels Of Sportsman High School Students. Gaziantep University Journal Of Sport Sciences, 2(4), 20-31.

2. WTF.CompetitionRules.http://www.wtf.org/wtf eng/site/rules/competit ion.html. 2021 Accessed: 22 Jan 2021.

3. Bridge CA, Santos JFS, Chaabène H, Pieter W, Franchini E. Physical and physiological profile of taekwondo athletes. Sports Med. 2014 44: 713-733.

4. García ADF, Oliva FJC. An evaluation of categories for tactical actions: A preliminary study of combat analysis in taekwondo. Cult Cienc Deporte. 2016 12: 157-170.

5. Kazemi M, Ong M, Pacis A, Tseng K. A profile of 2012 Olympic Games taekwondo athletes. J Int Assoc Taekwondo Res. 2014 1: 12-18.

6. Ball N, Nolan E, Wheeler K. Anthropometrical, physiological, and tracked power profiles of elite taekwondo athletes 9 weeks before the Olympic competition phase. J Strength Cond Res. 2011 25: 27522763.

7. Santos VGF, Franchini E, Lima-Silva AE. Relationship between attack and skipping in taekwondo contests. J Strength Cond Res.2014 25: 1743-1751.

8. Melhim A. F. Aerobic and anaerobic power responses to the practice of taekwon-do. $\mathrm{Br} J$ Sports Med. 2001 35(4): 231-34. PMID: 11477015

9. Markovic G., Misigoj-Durakovic M., Trninic S. Fitness profile of elite Croatian female taekwondo athletes. Coll Antropol. 2005 29(1): 93-9. PMID: 16117305

10. Da Silva Santos JF, Wilson VD, Herrera-Valenzuela T, Machado
FSM. Time-Motion Analysis and Physiological Responses to Taekwondo Combat in Juvenile and Adult Athletes: A Systematic Review. Strength \& Conditioning Journal, 2020 42(2): 103-121.

11. Kazemi M, Casella C, Perri G. 2004 Olympic tae kwon do athlete profile. The Journal of the Canadian Chiropractic Association, 2009 53(2):144.

12. García-Pallarés J, Sánchez-Medina L, Pérez CE, Izquierdo-Gabarren $M$, Izquierdo $M$. Physiological effects of tapering and detraining in world-class kayakers. Med Sci Sports Exerc. 2010 42(6): 1209-14. doi: 10.1249/MSS.0b013e3181c9228c PMID: 19997013

13. Koundourakis NE, Androulakis NE, Malliaraki N, Tsatsanis C Venihaki M, Margioris AN. Discrepancy between exercise performance, body composition, and sex steroid response after a sixweek detraining period in professional soccer players. PLoS ONE. 2014 9(2): e87803. doi:10.1371/journal. pone.0087803 PMID: 24586293.

14. World Medical Association. Declaration of Helsinki-Ethical Principles for Medical Research Involving Human Subjects. World Medical Association. 2019. https://www.wma.net/policies-post/wmadeclaration

15. Zorba E, Ziyagil M, Çolak H, Kalkavan A, Kolukısa S, Torun K, Özdağ $\mathrm{S}$. Comparison of Anthropometric and Physical Fitness Values of 1215 Age Group Football Players with the Sedentary Group. Hacettepe University. Science and Technology Football Journal.1995 40.

16. Durning JVGA, Womersley J. Body fat assessed from total body density and its estimation from skinfold thickness-measurements on 481 men and women aged from 16 to 72 years, British Journal of Nutrition, 197432 (1):77-97

17. Siri WE. The gross composition of the body. In C.A. ToBIAs \& J.H Law- rence (Eds.), Advances in biological and medical physics. New York: Aca- demic. 1956

18. Bostancı Ö, Uzun A, Emirzeoğlu M, Kabadayıl M, Şahin B, Bilgiç $S$. Investigation of Height-Body Relationships with Some Anthropometric Measurements of Football Players who are Students at the School of Physical Education and Sports. Atatürk University Journal of Physical Education and Sports Sciences, 20046 (2) :1-9.

19. Hoffman JR. Physiology of basketball. In: Basketbatt. D.B. McKeag ed. Oxford: Blackwell Science, 2003 pp. 12-24.

20. Scheller A, Rask B. A protocol for the health and fitness assessment of NBA players. Ctin. Sports Med.1993 12:193-205.

21. Kim HB, Stebbins CL, Chai, JH, Song J.K. Taekwondo training and fitness in female adolescents. Journal of sports sciences. $201129(2)$ : 133-138.

22. Stanforth PR, Crim BN, Stanforth D, Stults-Kolehmainen MA. Body composition changes among female NCAA division 1 athletes across the competitive season and over a multiyear time frame. J Strength Cond Res 2014 28(2):300-307.

23. Casajus JA. Seasonal variation in fitness variables in professional soccer player. J Sports Med Phys Fitness 2001 41(4):463-469.

24. Duthie G, Pyne D, Hooper S. Applied physiology and game analysis of rugby union. Sports Med 2003 33:973-991.

25. Pitts S, Blood E, Divasta A, Gordon CM. Percentage body fat by dual energy X-ray absorptiometry is associated with menstrual recovery in adolescents with anorexia nervosa. J Adolesc Health. 2014 54(6):739- 741

26. Arabacı R, Görgülü R, Çatıkkaş F. Relationship Between Agility and Speed, Reaction Time and Body Mass Index in Taekwondo Athletes. Sport Sciences, 2010 5(2): 71-77.

27. Badem E.A, Kocahan T, Akınoğlu B, Tortu E, ışık H, Hasanoğlu A. The Effect of Potential Renal Acid Load on Isokinetic Muscle Strength of Knee Extensor Muscles and Anaerobic Performance in Taekwondo Athletes. Turkey Clinics Sports Sciences. 2021 13(2).

28. Ölmez C, Vedat A, Yüksek S, Öztaş M, Civil T. Investigation of the relationship between somatotype structures and performance characteristics of 11-13 years old male taekwondo athletes. National Journal of Sport Sciences. 2018 3(1): 1-13.

29. Mavi S. Physical and Motoric Properties in Taekwondo. Iğdır University Journal of Sport Sciences, 2018 1(1): 1-15. 